\title{
man \\ Optimization of Industry 4.0 Implementation Selection Process towards Enhancement of a Manual Assembly Line
}

\author{
Amanda Aljinović, Nikola Gjeldum, Boženko Bilić and Marko Mladineo *(D) \\ Faculty of Electrical Engineering, Mechanical Engineering and Naval Architecture, University of Split, \\ R. Boskovica 32, 21000 Split, Croatia; amaljino@fesb.hr (A.A.); ngjeldum@fesb.hr (N.G.); bbilic@fesb.hr (B.B.) \\ * Correspondence: mmladine@fesb.hr; Tel.: +385-21-305-939
}

check for updates

Citation: Aljinović, A.; Gjeldum, N.; Bilić, B.; Mladineo, M. Optimization of Industry 4.0 Implementation Selection Process towards

Enhancement of a Manual Assembly Line. Energies 2022, 15, 30.

https://doi.org/10.3390/en15010030

Academic Editor: Wen-Hsien Tsai

Received: 29 November 2021

Accepted: 17 December 2021

Published: 21 December 2021

Publisher's Note: MDPI stays neutral with regard to jurisdictional claims in published maps and institutional affiliations.

Copyright: (C) 2021 by the authors. Licensee MDPI, Basel, Switzerland. This article is an open access article distributed under the terms and conditions of the Creative Commons Attribution (CC BY) license (https:// creativecommons.org/licenses/by/ $4.0 /)$.

\begin{abstract}
Last year's developments are characterized by a dramatic drop in customer demand leading to stiff competition and more challenges that each enterprise needs to cope with in a globalized market. Production in low-mix/high-volume batches is replaced with low-volume/high-variety production, which demands excessive information flow throughout production facilities. To cope with the excessive information flow, this production paradigm requires the integration of new advanced technology within production that enables the transformation of production towards smart production, i.e., towards Industry 4.0. The procedure that helps the decision-makers to select the most appropriate I4.0 technology to integrate within the current assembly line considering the expected outcomes of KPIs are not significantly been the subject of the research in the literature. Therefore, this research proposes a conceptual procedure that focus on the current state of the individual assembly line and proposes the technology to implement. The proposed solution is aligned with the expected strategic goals of the company since procedure takes into consideration value from the end-user perspective, current production plans, scheduling, throughput, and other relevant manufacturing metrics. The validation of the method was conducted on a real assembly line. The results of the validation study emphasize the importance of the individual approach for each assembly line since the preferences of the user as well as his diversified needs and possibilities affect the optimal technology selection.
\end{abstract}

Keywords: Industry 4.0; assembly line; information flow; decision making

\section{Introduction}

Globalization has created considerable challenges that production-oriented enterprises need to tackle: fierce competition, short windows of market opportunity, frequent launches of products and large-scale alternations in product demand [1]. The milestone for industry surely is the last year's events developments, followed by the dramatic change in customer demands. Therefore, in order to survive the turbulences on today's market, flexibility, scalability and agility have to be primary objectives for any enterprise. In addition, high degree of specialization while maintaining flexible and fast response on customer demands is the characteristic that today's enterprise needs to own. Many manufacturing enterprises have oriented their production towards more agile production approaches instead of mass production [2], in order to take opportunities enabled by market widening, where all competitors have similar opportunities, and customer demands more customized or even personalized products.

Manufacturing, as a cornerstone of the developed nations' economy, presents a strong base for any advanced country. Besides encouraging and stimulating all the other economic sectors, manufacturing provides a wide range of different jobs, thus enabling higher standards of living. Croatia's manufacturing industry has predominant lack of competitiveness due to inherent problems and obstacles. The initial plan for last three decades-to restructure the economic subjects efficiently to become competitive enough with-global markets, failed due to some transitional problems and previous economic system anomalies. Today, 
low industry subjects' productivity is additionally burdened by an oversized government administration, the disproportionate number of workers, obsolete technology, and lack of digitalization. Unfortunately, insufficient education of personnel in the management field, contributes to additional lagging back when compared with competitors around the globe. The lag is emphasized in the field of manufacturing personnel's lifelong learning, apathy, and idealess of management for the implementation of advanced organizational methodologies. Individual investments in cutting-edge technologies often do not result in expected outcomes, as those are implemented without proper education and management. The majority of public enterprises disappeared in the failed and corruptive privatization process, and those that managed to survive, have undergone numerous restructuring programs to avoid liquidation. In these conditions, small and medium-sized enterprises (SME) did not have sufficient support from the government administration nor by large industrial systems. Due to all these facts, economic development has been mostly turned to the service sector, especially tourism, which is turned to be crucial mistake, considering the world crisis in 2020.

Rapid response to customer demands represents a key factor of the company's survival [3]. The switch to Reconfigurable Manufacturing System (RMS) could be a solution. RMS has three major principles [1]: it ensure adaptable production resources in order to respond to unpredictable market demands and system behavior uncertainty, it is designed to produce all members of the product family, rather than single product and its system core features should be incorporated in it components (mechanical, communications and control), as well as the system as a whole. Therefore, RMS possesses flexibility of flexible manufacturing systems and productivity of dedicated manufacturing Lines [4]. Switching from a traditional manufacturing system to RMS leads toward the so-called living factory [4] or Smart Factory [5]. Such a factory can rapidly respond to the needs of customers while maintaining low manufacturing costs and high levels of quality [1]. The Smart Factory introduces Smart Product to production, that are uniquely identifiable and traced to be located any time [6]. Knowing their own history, current status and alternative routes to achieving their target state, makes the product unique (single-item) $[7,8]$. Smart Factories could make single item production profitable and therefore allows individual customer requirements.

To address and overcome the current challenges of shorter product lifecycles and individual customer requirements concept Industry 4.0 (I4.0) [9-11] is introduced to manufacturing systems. I4.0 [5] focuses on the establishment of products and production processes thus emphasizing the needed transformation of today's factories into Smart Factories for the production of Smart Products that are networked in an Internet of Things (IoT). A possibly worldwide network of interconnected and uniform addresses objects that communicate via a standard protocol could be considered as IoT [12]. Therefore, IoT enables the collection of production real-time data and it's exchanging among systems within factory, machine tools, workers and even customers. Information availability presents a crucial factor that enables response, almost in a real-time manner, to the changeable market demands by the rapid adjustment of an existing manufacturing system [13].

The aim of I4.0 is to achieve monitoring and synchronization of data between the physical factory floor and cyberspace. Digitalization of the manufacturing process results with some level of cognition if the information from all connected systems are collected, mutually summarized, analyzed and used for further actions [14]. That defines the manufacturing as "smart". Based on the [15], total 10 I4.0 transformation pillars can be defined: IoT, cloud computing, cyber-physical system, big data, autonomous robots, simulation, horizontal and vertical integration, additive manufacturing, augmented reality, and blockchain. Transition to a Smart Factory affects the workers in many ways, and the workers are considered as the main value of every company. In order to successfully transform to I4.0 and therefore ensure their own survival, enterprises must continuously implement newly developed methods, technologies and skills. In order to acquire practical experience and upgrade the necessary knowledge and competences about I4.0, enterprises need to continuously 
invest in workers' education. Using the concept of the Learning Factory (LF) presents an emerging method of how this can be achieved.

To cope with the challenges set by the I4.0 related equipment implementation and workers' education to work with, the academic institutions worldwide and some large industrial enterprises are developing a new nearly realistic factory environment for education and research called LF. After the occurrence of I4.0, diverse academic institutions have invested in their conventional LF in order to develop and build I4.0-based LF that serves as a good polygon for the transformation of the new concepts of I4.0 toward their students and industry workers. If managed properly, LFs enables students and workers introduction to the latest advancements in I4.0 and achievable results of the manufacturing and Information and Communication Technology (ICT) integration [16]. A realistic environment to test the basic engineering principles of I4.0 equipment could be achieved in LFs environment [17]. Within LFs, process improvement could be validated without cost pressure that appears in the real industrial environment. Moreover, LFs give the students and workers the ability to understand the behavior of real production systems, and the opportunity to apply different improvement scenarios in order to explore possible outcomes [18]. In order to gain workers' knowledge faster, LFs have to offer insight into innovations that can be applied in a real industry environment in order to get practical experience and skills timely $[16,19]$. So, they become prepared and skilled for operation in the I4.0 environment or to upgrade the conventional production systems to become smart production systems. It is expected that the number of LFs will increase in the upcoming years due to the increasing demand for better forms of learning [20].

Collaboration between academic institutions and industry is crucial and can be established by LFs. Producing knowledge through research, diffusing knowledge through education as well as using and applying knowledge through innovation is the appropriate approach, known as "the knowledge triangle". Academic institutions and industrial training facilities have to continuously adapt and enhance their education concepts and methods, in order to conform to future job profiles and related competency requirements. As innovative learning environments, LFs mostly act in an interdisciplinary manner, which has proven to be an effective concept addressing these challenges [21]. The LFs' mission is to integrate design, manufacturing and business realities into the engineering curriculum, especially by introducing hands-on experience in design, manufacturing, and product realization [22]. This is accomplished by providing the balance between engineering science and engineering practice $[23,24]$.

Experimental research for this article was performed in the LF at the Faculty of Electrical Engineering, Mechanical Engineering and Naval Architecture, University of Split, Croatia [25]. This LF is called the Lean Learning Factory (LLF), as its initial goal, during its development, was to teach lean tools and methods by hands-on simulations. Lean management tools and methods detect any activity which does not add value to the product as waste and remove those from the production process [26]. Together with optimizing activities that are necessary, but do not add value (non-value added activities), the ultimate goal is to reduce costs, needed resources, and total production time. I4.0 enables the computerization of the so-called third industrial revolution, thus making the manufacturing process smarter, more effective and productive. In the literature, it can be found that the lean concept acts as a basis and prerequisite for I4.0 implementation [27]. In [28], another author emphasized the importance of the lean management implementation to a certain level for adopting any new methodologies, including I4.0. Therefore, upgrading LLF from pure lean method training to the I4.0 demonstration and training facility could be considered an appropriate development path. Besides research and development of some I4.0 related equipment, for laboratory usage, demonstration of I4.0 related equipment integration in the production system will remain the main focus in further LLF development. It is found the recently built smart LFs worldwide train the students and workers on how the real I4.0-based smart factory operates rather than teaching the core concepts of I4.0 
related equipment and the transformation process to achieve I4.0-based smart factory in the first place [29].

Through equipment used in real industry and specially developed equipment that imitates real industry equipment, supplemented with specialized equipment for learning purposes, LF is established for research, development, demonstration and knowledge transfer to the economy [17]. The knowledge is transferred by training students in the last stages of graduate and postgraduate studies, as well as industry workers, that are trained in LLF on a different basis. Some annual conferences held at the University of Split, FESB, have workshops and activities in LLF. Individual projects with industry partners on enhancing workers' skills are mostly held in LLF to convince participants of tools and methods purposefulness. Internationally funded projects that are mainly focused on the enhancement of fundamental science achievements on scientific and academic institutions, enables the introduction of developed methods and tools to partners from industry. LLF is therefore again an appropriate facility to demonstrate project outcomes, to industry partners' management and to industry workers. The aforementioned activities in LLF require both specially developed didactic equipment and real industry equipment.

An assembly line (AL) presents a final step of the production system. It consists of consecutive workstations. On each workstation operators, i.e., workers, sequentially perform a subset of assigned assembly tasks in order to create the required subassembly or finished product within a given time range. The assembly line, called the traditional assembly line, is first introduced by Henry Ford as a tool that was supposed to fulfill the growing customer needs for the single product model while ensuring productivity growth together with total production cost reduction [30]. However, in today's industrial environment where change and unpredictability of market demand have become a constant, traditional ALs are no longer convenient. Therefore, new flexible assembly systems are requisite to deal with the required high product variety. The era of I4.0 and its related technology provides the opportunity for assembly systems to adapt to the challenges of today's global marketplace. If applied correctly, I4.0 technology can significantly contribute to higher flexibility, robustness and productivity of the $\mathrm{AL}$, as well as product variety and traceability [31]. Furthermore, in order to maintain the high flexibility of the system, workforce adaptability to changes are essential. Therefore, humans still play a prime role in ALs [32], especially when it comes to assembling complex mechanical parts such as gearboxes [33]. Manual assembly is often paper-based and contains a huge amount of information about the product components of which a certain amount of information may be unnecessary and redundant [34]. Due to the variety of products and their dynamic production in today manufacturing that is characterized by low-volume/high variety of product, information that the workers must process to finished their tasks increase [35]. It means that the workers' are confronted with additional effort during their task execution that can affect their ability to comprehend complex assembly relations and consequently, increase the workers' tendency for errors. From this perspective, technologies adopted from I4.0 can provide aid and support to humans, i.e., workers, to execute the assembly task in the most effective way and consequently significantly affect the assembly system's improvement [32,36]. This is particularly true for technologies such as digital instructions, cobots, radio-frequency identification (RFID) technology and other I4.0 advanced technologies that can be deployed to improve humans' abilities.

The AL developed within the LLF seek to mimic the real industrial world as close as possible. It implies that ALs can be designed bearing in mind the utilization of equipment that is used in real industrial plants in order to produce an actual product (e.g., the gearbox), equipment such as real hand-operated tools and implements, conveyors, supermarkets, etc. Therefore, case studies applied in them can be contemplated as valuable case studies for industry [37]. Didactic games used for assembly simulation process within LLF at the University of Split entails assembly process of toy trucks and toy formulas and reworked simulation game "Lego flowcar ${ }^{\circledR}$ ". In the first case where the assembly process of toys is considered, the AL consists of four workstations. Each participant has to map the assembly 
process according to VDI 2860 standard. When the mapping process is over, the participant is encouraged to analyze and suggest improvement of the assembly process in order to reduce the total assembly time, as well as to propose improvements in assembly line design that enables easier adjustment of assembly to automation. The second didactic game implies the usage of methods associated with warehousing and logistics systems. This simulation game includes also learning methods for workload balancing on assembly stations. Since the observed didactic games involve the assembly of toys, from the perspective of the participants, these games are not taken seriously. In order to convince the participants that the application of the methods used in didactic games executes similar results as in the assembly of real products, additional efforts were made and a gearbox assembly line was developed. Car gearboxes originate from two car models and they are produced at the factory "Zastava Automobiles". Two versions of gearbox cases, together with the high variety of different components that can be fitted, results in more than 20 diverse final goods. The product AL comprises five different workstations where the elements of ICT are installed. Therefore, the gearbox assembly line will be used as a case study for this paper.

The paper is organized in the following way: motivation and research gap are presented in Section 2; framework of proposed procedure for the evaluation of the most appropriate I4.0 technology to implement is presented in Section 3; assembly line that is used as a validation study, problem definition and implementation of the proposed decision support system is presented in Section 4; discussion and conclusion are presented in the last Section.

\section{Motivation for the Proposed Procedure}

I4.0 technologies are new ways that can facilitate and assist human operators during the execution of their tasks, enabling them cognitive and physical support as well as a safe environment since man is still a vital factor in manufacturing [32,38]. The introduction of new technologies within the AL must be accompanied by progress in terms of system performances, operators' well-being, and economic outcomes. Therefore, an analysis of the circumstances under which it is worthwhile to introduce new technologies is necessary [39].

To the author's knowledge, most of the reported research in the literature focused on the investigation of limitations/possibilities of the implementation of new specific I4.0 technology within manual AL, during which they focus only on one technology as a possibility. For example, one of the topics that authors often deal with is the exploration of the possibilities of applying human-robot collaboration (HRC) within the AL through the distribution of tasks between these two subjects. In these papers, the justification for the introduction of the HRC or fully automated robotic assembly in regards to traditional manual assembly is examined through the comparison of these three cases in terms of important assembly measurable performances such as total task time, batch sizes, throughput, production cost, total time etc. [37,40-43]. Uva et al. [44], Horejsi et al. [45] and Mourtzis et al. [38] investigate applicability and the effectiveness of augmented reality applications compared to traditional method (paper manual instructions). Effectiveness was investigated in terms of comparison of overall execution task time, mental demand, physical demand, errors, etc. In the paper of Wolfartsberger et al. [46], the authors point out that many technologies are not yet at a level that they can be implemented in practice, therefore they gave a review of the current technologies that support manuals assembly activities and a review on the future perspective of these technologies. Observed technologies that support assembly tasks with respect to their practical implementation in companies are HRC and instructive assistance systems (mixed and virtual reality). Hou et al. [34,47] focus on the benefits that digital instructions bring compared to paper based instruction in terms of assembly time and number of error. Yoo et al. [48] investigate the important factors for cloud computing adoption, while Marinho et al. [49] proposed decision support for I4.0 that guides decision makers in adoption of cloud enterprise resource planning. Majdzik et al. [50] proposed approach that focused on the concurrency and synchronization problem between assembly line and AGV. 
Papers that are focused on the comparison of different technologies that can support assembly activities of a certain assembly line are not significantly represented in the literature. The selected technology for implementation in the assembly line should consider the economic, spatial, and cost-effective aspects and need to be aligned with the expected strategic goals of the company. A step towards that was found in the research of Peron et al. [36]. In this research, the authors investigate the possibility of applying two I4.0 technologies that assist in assembly activities. The authors proposed a conceptual decision support model for implementing cobots and digital instructions within the AL observing the cost-effectiveness of their use considering the time of task execution, throughput, cost of equipment and labor cost of workers. The framework provides guidelines that, based on the observed parameter levels, narrow the possibilities for further option configuration consideration. However, the proposed approach was developed taking into account only one product model, it means that the impact of product diversity, which is a characteristic of today's production, was neglected. Moreover, the conducted validation study showed a mismatch between the experimental solution and the solution obtained by applying this approach.

Therefore, to the best of the author's knowledge, the procedure that helps the decisionmakers to select the most appropriate I4.0 technology to integrate within the current assembly line considering the expected outcomes of KPIs are not significantly been the subject in the literature. It can be noticed that the majority of the researches that deal with some kind of optimization, used only objective measurable data neglecting managers' perspectives, i.e., development strategy and uniqueness of each individual company. In accordance with that, the alignment of expected benefits with the overall strategic goal is omitted. Companies differently cope with the introduction of new technologies depending on the technological and management abilities they own. In order to achieve maximum benefits of new technologies, each company needs to better comprehend and focus on proper technologies and their applicability in their unique environment. In fact, a comprehensive and respective tool has not yet been developed that estimates the benefits of I4.0 technology and proposes the most appropriate technology, having in mind the individual needs and possibilities of the company. Therefore, the need for a decision support system that guides companies in their path of choosing the most appropriate technology, i.e., technology from which they will benefit the most, is noticed. This support system has to include both, objective measurable data and a dose of subjectivity in the decision-making process along with the criteria interdependence. The importance of inclusion of a dose of subjectivity in the decision processes during the transformation of the manufacturing towards I4.0 is also emphasized in the research by Erdogan et al. [51] where authors conclude that "leadership" is the most important criteria for finding the best strategy to transfer to I4.0. Considering the role and importance of advanced technology as enablers of I4.0 as well as the diversity of strategic aims and needs of different companies, a framework for I4.0 technology selection within the assembly line is proposed in this research. The proposed framework leads to the selection of the most appropriate I4.0 technology considering the individual criteria constraints and criteria interdependence along with the decision makers' preferences. Procedure is goal oriented, therefore it lead decision-makers to be more effective already in the first procedure step. In comparison to the approaches found in the literature, this procedure leads decision-makers to the selection of the most appropriate technology that is optimized according to the expected improvement of key performance indicators (KPI). The aim is to propose simple, efficient and easily understandable decision support system that can be readily applicable in the manufacturing context.

\section{The Selection Process of the Most Appropriate I4.0 Technology}

The procedure of selecting the most appropriate I4.0 technology that leads towards the enhancement of manual assembly is presented in this paper. Among the measurable criteria that were used to evaluate the selection process, the procedure will take into account the preferences of decision-makers thus enabling that subjectivism enters into 
the analysis. The existence of a dose of subjectivity in today's production is crucial. The usage of weights (priorities) for each observed criteria, can enable decision-makers to find the best compromise solution of the observed problem that is in accordance with the development strategy as well as with the limitations/capabilities of the company. To select the most appropriate I4.0 technology for the improvement of the AL, this study provides a general framework with three main steps, as presented in a schematic view in Figure 1. The proposed framework implies the usage of technologies that have the potency to improve the performances of the AL process by enabling constant interaction between an operator and his/her workstation.

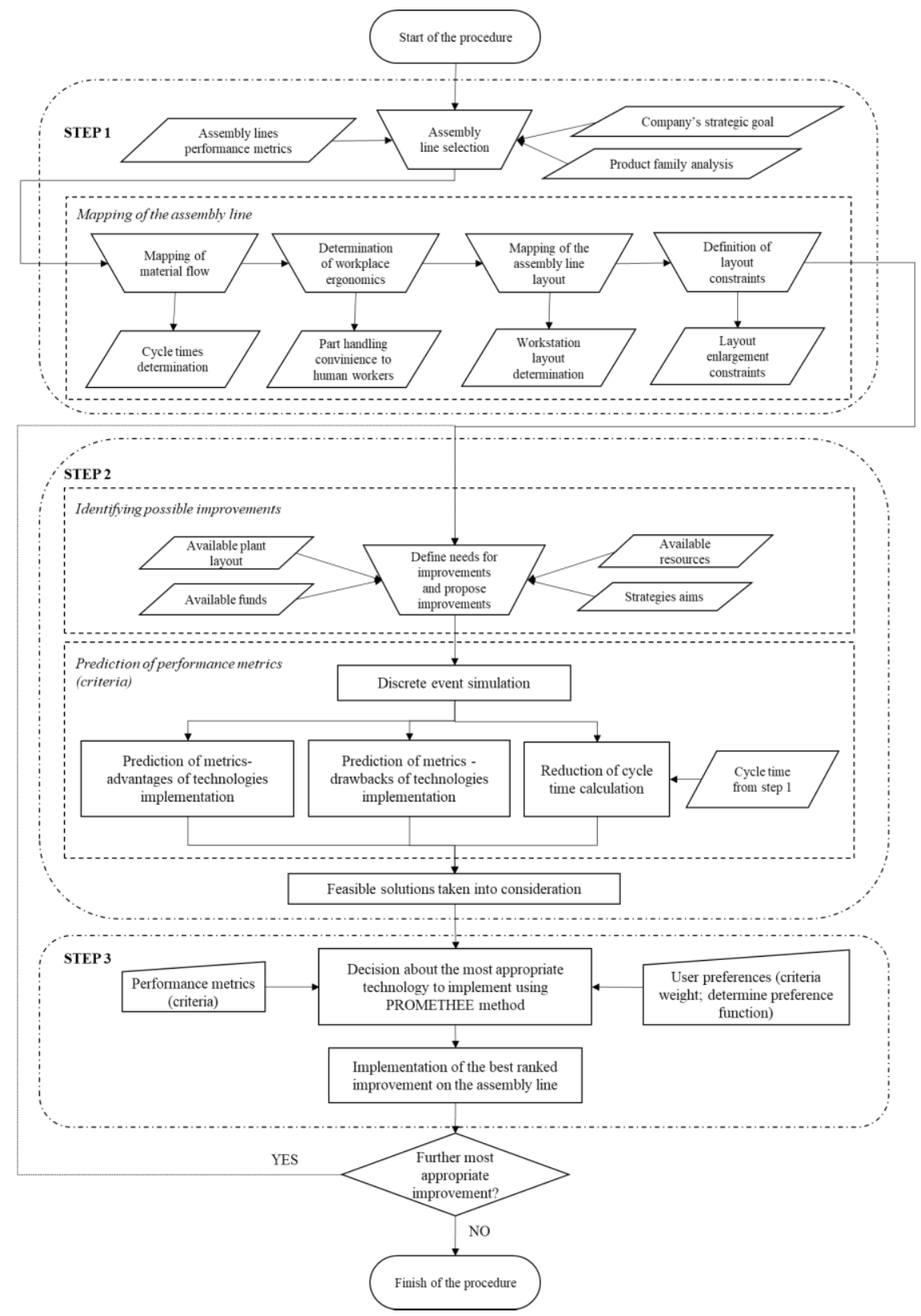

Figure 1. The proposed procedure for the evaluation of the most appropriate technology to implement.

In the first step of the procedure, according to the performance metrics and the company's strategic development aims, the AL that needs improvement is identified. AL under consideration for the improvement process by applying I4.0 technologies is confronted with problems such as unbalanced workflow, a high percentage of tasks performed by operators, 
unbalanced operators' utilization, high physical or mental workload of the human, high process time variations, long lead times that disrupt flexibility of $\mathrm{AL}$, etc. When the line is selected, in order to evaluate the current situation and to detect issues and the possible locations for enhancements material and information flow mapping has to be done. In addition, constraints and potentiality of assembly layout should be perceived and taken into consideration, as well as other constraints that the company is confronted with. The main idea of this step is the evaluation of current performance of the AL which gives the managers, i.e., decision-makers a clear idea about performances of the line and directs them towards their strength and weaknesses in order to identify the improvement possibilities.

Prior to the I4.0 technology implementation, possible improvements of the mapped AL process condition through the commonly used methods, such as work standardization, achieving the workload balance of the assembly line, and ensuring the proper workplace ergonomics, should be considered. These previous actions may result in certain improvements in key performance indicators (KPIs) before the introduction of I4.0 technology and serve as a good foundation for further improvements.

In the second step, considering the limitations and possibilities of the $\mathrm{AL}$, as well as available company's resources and strategic goals, possible improvements, in terms of different technologies that can be used, are identified. The proposed list of feasible comparable options along the whole AL serves as an input parameter for the last step of the procedure where feasible solutions are ranked according to the defined KPIs and strategic goals. Tools such as discrete event simulation can be used to predict the outcomes of the proposed technology. Outcomes refer to the KPIs that the company puts in focus as important factors through which they evaluate potential progress. To evaluate potential improvements most of the companies uses traditional KPIs such as costs, quality, line productivity, cycle time, energy consumption, throughput time, etc., but the Miqueo et al. [32] emphasize the need for new indicators that are unique for the product family, operational context and business objectives of company whose assembly system is observed. The improvement outcomes of possible technology applications should be estimated quantitatively because only measurable objective data can serve as a proper measure for optimization of the observed process.

Besides the list of feasible solutions, as input parameters in the last step of the decision support system, metrics noticed as important KPIs from prediction tools in the case of implementation of each proposed option (solution) are also used. A decision support system based on the PROMETHEE method (preference ranking organization method for enrichment evaluation) is proposed to support the multi-criteria decision-making process during the evaluation and selection of the most appropriate technology that is in line with the manufacturing and business goals and needs of the organization. PROMETHEE is an effective and significant multi-criteria decision analysis tool, it means that this method is well suited for problems where a finite set of alternatives subjected to multiple conflicting criteria has to be scalarized according to solution desirability [52,53]. The decision-makers' preferences can be set as any combination of quantitative data and the corresponding preference function of each criterion. Quantitative data are called weight (priorities) and they describe the importance of each criterion from decision makers' point of view. The sum of the weights of all the criteria is always equal to $100 \%$. While, the preference function describes how the deviations between the assessments of two alternatives on a certain criterion should be contemplated [54]. PROMETHEE method can be briefly described through the five steps [54]. When the criteria and alternatives of a decision problem are defined, first step refers the assigning weights to each criterion and conducting the pairwise comparison in order to determine deviations between assessments of alternatives in regards to each criterion. The second step implies the selection of appropriate preference function, between six possible, for each criterion in order to model the way the decision-maker 
perceives the measurement scale of the criterion. The third step implies computing the global preference index:

$$
\forall a, b \in A, \quad \pi(\mathrm{a}, \mathrm{b})=\sum_{\mathrm{j}=1}^{\mathrm{k}} P_{j}(a, b) \times \mathrm{w}_{\mathrm{j}}
$$

where $\pi(a, b)$ is the global preference index of alternative $a$ over alternative $b, w_{j}$ is the weight (priority) of $j^{\text {th }}$ criterion, $P_{j}(a, b)$ is the value of preference function for $j$ th criterion when alternative $a$ is compared with alternative $b$.

The last two steps imply the computation of positive and negative preference outranking flows in order to rank all the alternatives from the best to the worst one according to the PROMETHEE I (partial ranking) and PROMETHEE II (complete ranking) ranking. Positive preference flow, $\Phi^{+}(a)$, measures the preference of alternative $a$ compared to others, while negative preference flow, $\Phi^{-}(a)$, measures how many other alternatives are preferred to alternative $a$. Formula for PROMETHEE I is given in the following equations:

$$
\begin{aligned}
& \Phi^{+}(a)=\frac{1}{n-1} \sum_{x \in A} \pi(a, x), \\
& \Phi^{-}(a)=\frac{1}{n-1} \sum_{x \in A} \pi(x, a),
\end{aligned}
$$

Formula for PROMETHEE II is given in the following formula:

$$
\Phi(a)=\Phi^{+}(a)-\Phi^{-}(a),
$$

where $\Phi(a)$ is the net outranking flow for each alternative.

The best-ranked solution, solution with the highest $\Phi(a)$ value, is the most appropriate element of I4.0 technology of which the AL benefits the most, i.e., that technology presents the best compromise solution based on the used criteria and their weights defined by the user.

The proposed procedure is implemented and validated through the study of the assembly process on the real complex product developed in the LLF environment.

\section{Validation of the Developed Procedure on the Assembly Line within LLF}

Assembly is the keystone manufacturing process where commodities (product parts) of all upstream manufacturing processes, from design through engineering, manufacturing and logistics are joined in order to produce and offer a functional product [55]. Assembly of complex mechanical parts, such as gearboxes, is a characteristic of the automotive industry [33]. Due to the required effort and precision of their assembly process arising from the complexity of necessary tasks, their assembly is mostly done manually. However, it can be automatized, but automation implies excessive financial investment. Some companies such as Tesla Motors have attempted excessive automation in their AL. The conclusion that emerged from their automation attempt was that humans were underestimated [56].

The validation study used in this research is the car gearbox AL situated at the LLF. Car manual gearbox is a mechanical transmission device used for torque transfer from the car engine to wheels thus enabling both, the speed change by utilizing different transmission ratios as well as reverse car drive. It consists of a huge amount of different gears, gear levers, screws, shafts, etc. The gearbox is a multi-stage product, which means that its assembly process is carried in several steps, concretely five operations steps. Each step is assigned with a certain amount of work, and each step takes place at one workstation. Each workstation contains real hand tools and supermarkets with real parts. Workstations are connected with the conveyor. In each workstation, the assembly step relates to the insertion of an individual component (part) or sets of parts that presents one gearbox subassembly element. The example of manual gearbox used in this research is given in the Figure 2. 

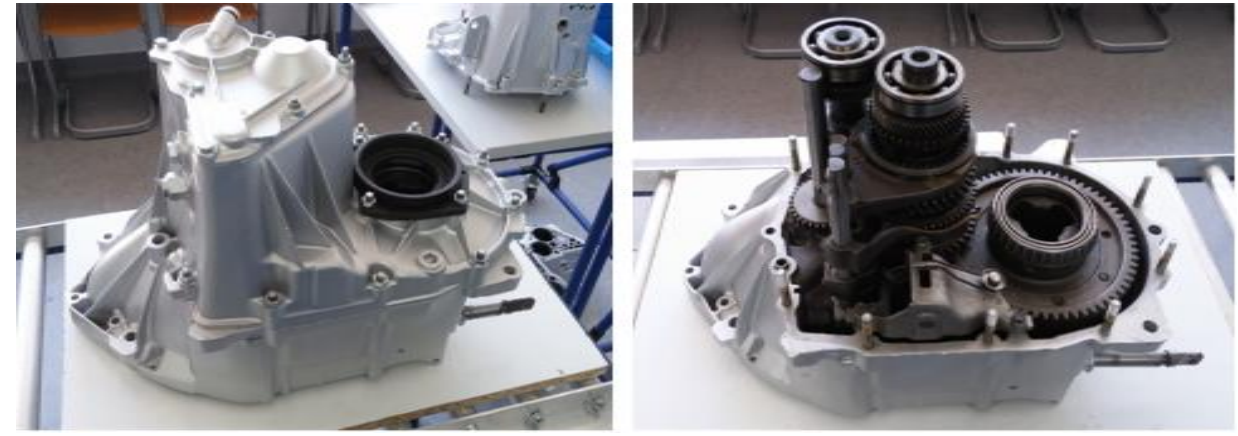

Figure 2. The assembled manual gearbox in LLF.

Gearbox AL was firstly introduced by Veza et al. [25] where the authors investigated the balancing procedure of the manual AL for only one product type using the paper instructions for workers. The further evolvement of the AL, presented by Gjeldum et al. [57], included introduction of five additional products types in order to simulate highvariety/low-volume production on the existing AL. The increase of product variety results in the inevitable increase in the number of different parts (components, subassemblies) and consequently the enormous growth of assembly information data, as well as the higher need for supermarket storage capacity. To cope with the enormous information data and to improve performances of AL, elements of I4.0 technology must be taken into account [58].

The first step towards the implementation of I4.0 technology is given by Gjeldum et al. [57] where authors presented the balancing procedure of the current state of the AL that refers to the assembly process with "the manual approach". "The manual approach" implies the usage of paper-based working instructions and manual data gathering by analysts (timing by stopwatch). Results of the balancing procedure indicate the huge discrepancy of cycle times among workstations. In order to improve work balance among workstations, further improvement of the AL is needed. The solution to this problem could be achieved with the introduction of I4.0 technology. Therefore, the presented gearbox AL represents an excellent polygon for conducting a validation study. The observed gearbox AL is shown in Figures 3 and 4.

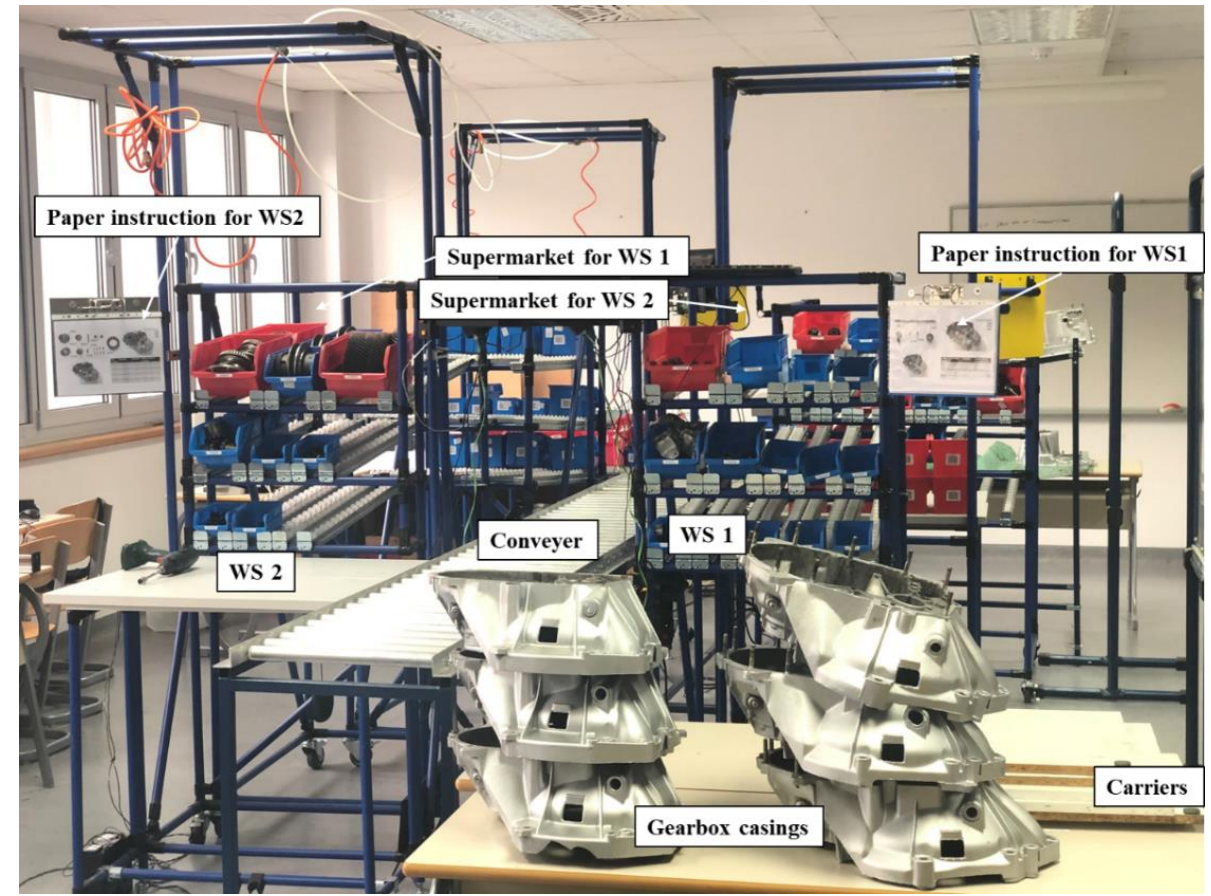

Figure 3. The gearbox assembly line in LLF. 


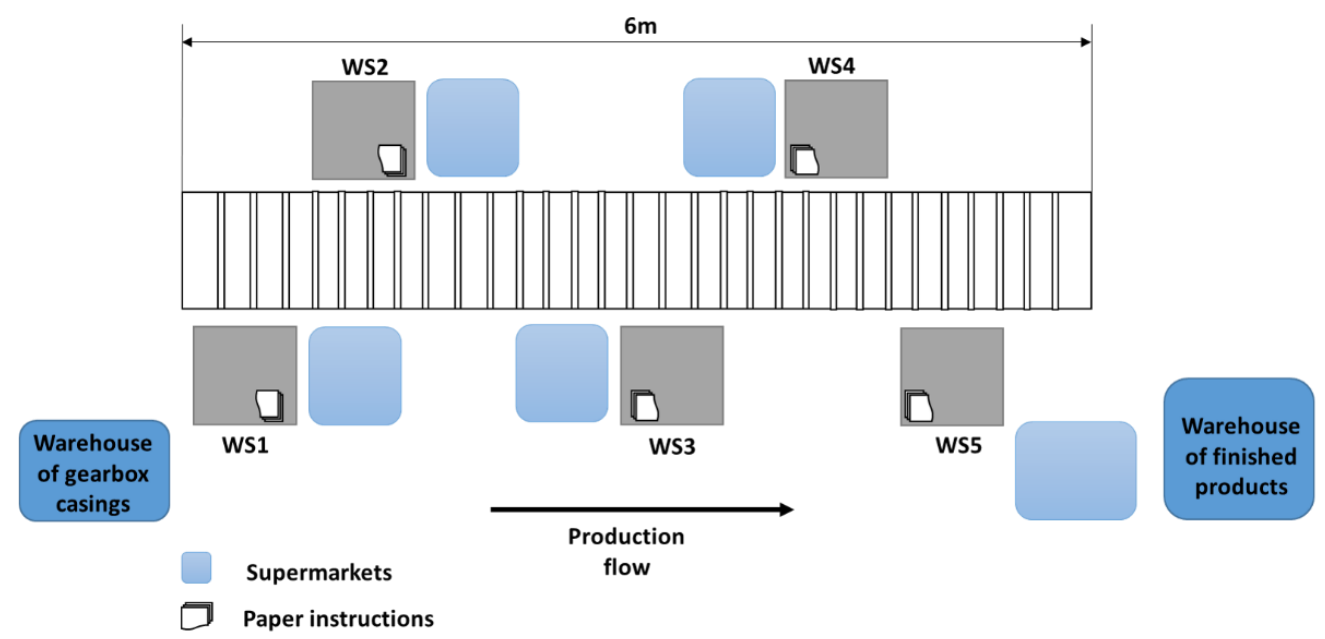

Figure 4. Top view of the gearbox assembly line.

According to the possibilities and limitations (available layout, resources and funds), as well as future strategic aims of gearbox AL development, in order to improve the yield of the assembly process, seven technologies of I4.0 are taken into consideration by presented decision support system approach. Enhancement that are taken into account are: RFID technology, Liquid Crystal Display (LCD), pick-by-light technology, augmented reality (AR), cobot, automated guided vehicle (AGV) and manipulator.

RFID technology is one of the most important technologies for automatic identification and tracking of commodities in production system. It enables precise information about the locations or states of observed goods in real-time and serves as a capstone for the establishment of the IoT within production [59]. Usage of digital instructions through LCDs instead of paper-based instructions are proved to reduce the assembly time of subassemblies/products as well as the number of errors [34,47] but only if the product is complex enough, as was stated by Syberfeldt et al. [60]. However, the meaning of the expression "complex enough" is not offered in their study. Besides the usage of digital instructions (LCD) utilization of technologies such as pick-by-light and AR also show positive impacts on assembly line performances in comparison with paper-based instructions. Pick-by-light implies the installation of a display with the light on certain shelves/boxes that contain the required parts. By light signalization, this technology guides the operators through the assembly steps, i.e., it displays screens lights up when a part has to be picked from a certain location and displays the required quantity to pick. This system is often connected with the warehouse management system. Therefore, some of the potential improvements that this technology brings are the reduction of picking time activities, as well as reduction of picking errors and operators' mental load [61,62]. When compared with paper-based instruction, AR also offers a significant improvement of the operators' performance time, error rate, cognitive (mental) load as well as minimization of the divided attention issue $[38,44,63]$. Noted recent research about the usage of AR technology for manufacturing purposes are papers of Zhu et al. [64], Schroeder et al. [65], Sepasgozar et al. [66] and Lalik et el. [67]. Zhu et al. [64] and Schroeder et al. [65] discussed the usage of AR technology as a tool that visualizes the Digital twin data, thus enabling the display of real-time information to the users. Sepasgozar et al. [66] presents the research about the application of the different AR technologies coupled with the Digital Twin for the virtual learning purposes while Lalik et al. [67] focus on the usage of AR technology together with the Digital Twin for the development of new system architecture for control of the industrial devices. Therefore, all of the mentioned technologies have the potential to improve the decision-making process and work procedure of the workers providing them with real-time information. Real-time information is necessary to enhance the timeliness and efficacy of the decision-making process [68]. 
Application of cobots within manual AL is desirable when the human is confronted with heavy loads and repetitive, tedious activities [69,70]. Human-robot collaboration (HRC) enables operators to share the same workspace with the cobots while proving the possibility to allocate tasks in a more flexible way [41]. If the tasks are assigned in an efficient way, this form of collaboration allows the system to evolve and rapidly accommodate the challenges of an increasing product variety and market volatility [71]. Tsarouchi et al. [72] and Kruger et al. [73] reported that the introduction of the cobots within the AL results in the reduction of time needed for a human operator to complete the task, higher efficiency, or the increase of human safety. On the other hand, some authors emphasize that implementation of the HRC is not always justified and may result in an increase in assembly time $[69,74]$. Justification and possibilities of cobot implementation within the gearbox assembly line that is observed within this research can be found in the previous paper of the authors [75]. Besides the cobot implementation, manipulator and AGV are considered in this research as technologies that coexist with the human in the workspace and reduce its physical load. AGV presents one of the most suitable and efficient technologies that can replace human work in the terms of goods' real-time supply and transportation within the factory environment. Manipulator is an electronic device developed to improve the ergonomics of the fifth assembly workstation, i.e., this device is developed to reduce operator physical effort, which occurs as a result of handling heavy components that need to be mounted (upper housing cover).

In the following subsection, the decision support system for I4.0 technology implementation is presented. The proposed approach is able to include user preferences that are associated with company constraints from an economic and practical point of view, as well as worker resource shortages.

\subsection{Implementation of Decision Support System}

For evaluating the use of different I4.0 technologies that can be utilized for AL development, this work proposes a decision support approach presented in Figure 1 that utilizes PROMETHEE method as a proven multi-criteria decision-making method. There are also other proven and widely used multi-criteria decision-making methods, such as: AHP, ELECTRE, and TOPSIS. However, PROMETHEE method was selected, because it was much easier to define indifference and preference thresholds of criteria as PROMETHEE method does, than to manually compare alternatives on each criterion as the AHP method does, and its approach is more convenient than the ideal and anti-ideal alternative approach of the TOPSIS method. Furthermore, PROMETHEE method is a modern version of the outranking approach that is used by ELECTRE method. By the proposed approach, seven options (alternatives) of I4.0 technologies are taken into account for the presented study, as was previously stated. These alternatives are evaluated through the four quantitative criteria: total investment cost, worker effort, workspace utilization and cycle time reduction. Each criterion is assigned a desired goal function, minimization or maximization. Two of the chosen criteria are intended to be maximized, namely "Cycle time reduction" and "Worker effort reduction". While the other two criteria are planned to be minimized. Criteria selected for this study, with their evaluation for every observed technology are shown in Figure 5.

Cycle time reduction is one of the main aims of the implementation of I4.0 technology since the total production time depends on the workstation with the highest cycle time. Information about cycle time reduction is gathered for feasible technology in relation to manual assembly. To collect this data, discrete event simulations are usually used, but in this research, the data are collected with the implementation of selected technology on a real AL that develops within LLF. The total investment cost is mainly affected by the price of the available equipment taken into consideration. Worker effort values are estimated according to the workers' experience and knowledge and they are collected through interviews with the different workers. Although, this factor can be more precisely calculated with the usage of some technologies, such as sensors or cameras, that provide information about 
physical worker effort according to the body gesture recognition [76], human physiology such as heart rate variability features [77], body movement and ability [78] etc. or by using approaches such as the one proposed by Blafos et al. [79]. Consequences of implementation of new technology always reflect in inevitable smaller or larger requirements of workspace layout. Since this resource is limited, it is taken into account. A presented list of criteria can be broadened and customizable to the company's strategy.

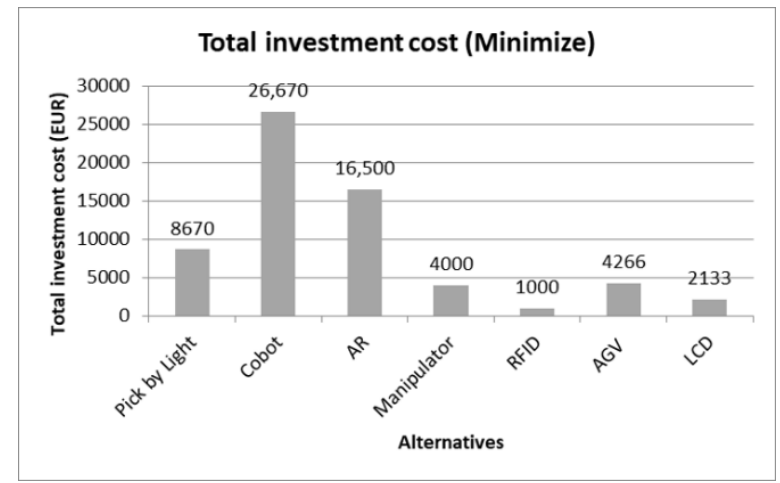

(a)

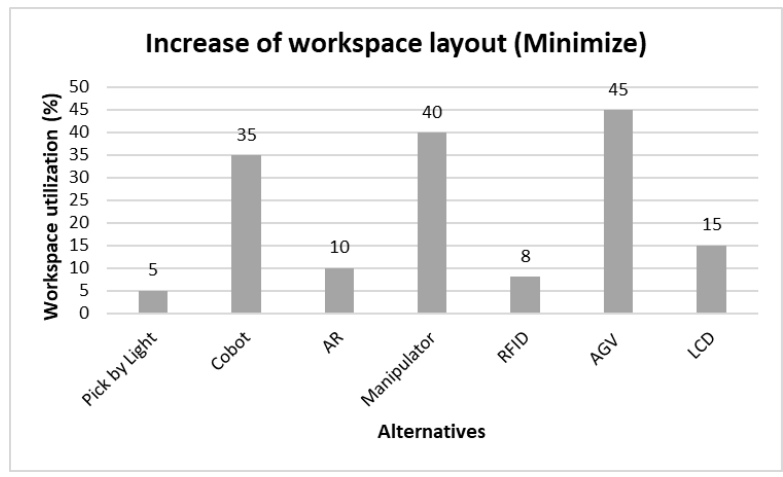

(c)

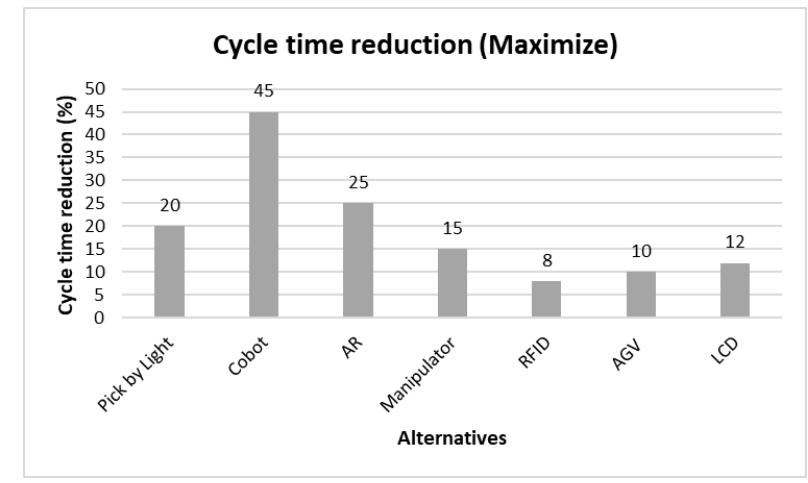

(b)

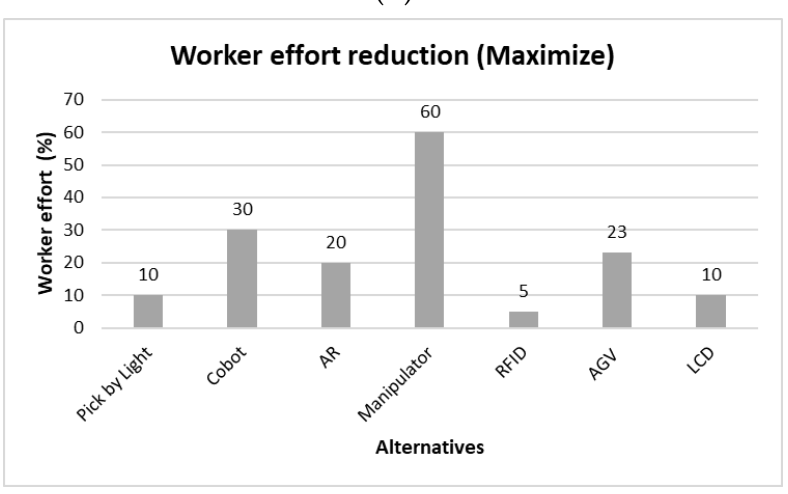

(d)

Figure 5. Criteria evaluation for each alternative: (a) total investment cost; (b) cycle time reduction; (c) worker effort reduction; (d) increase of workspace layout.

\subsection{Results}

The presented decision support system enables the decision-maker to express its preferences through criteria weight and preference function. For the study carried out in this research, five different criteria weights sets are observed. Each weight change refers to one scenario. The first scenario, named Scenario 0 , is an alternative where each criterion has equivalent weights. The other four scenarios refer to the options in which the weight value of one criterion differs from others. In doing so, one criterion was assigned twice the weight value than the remaining criterion weights (Scenario 1-4). The weights of five observed scenarios can be seen in Figure 6 . 


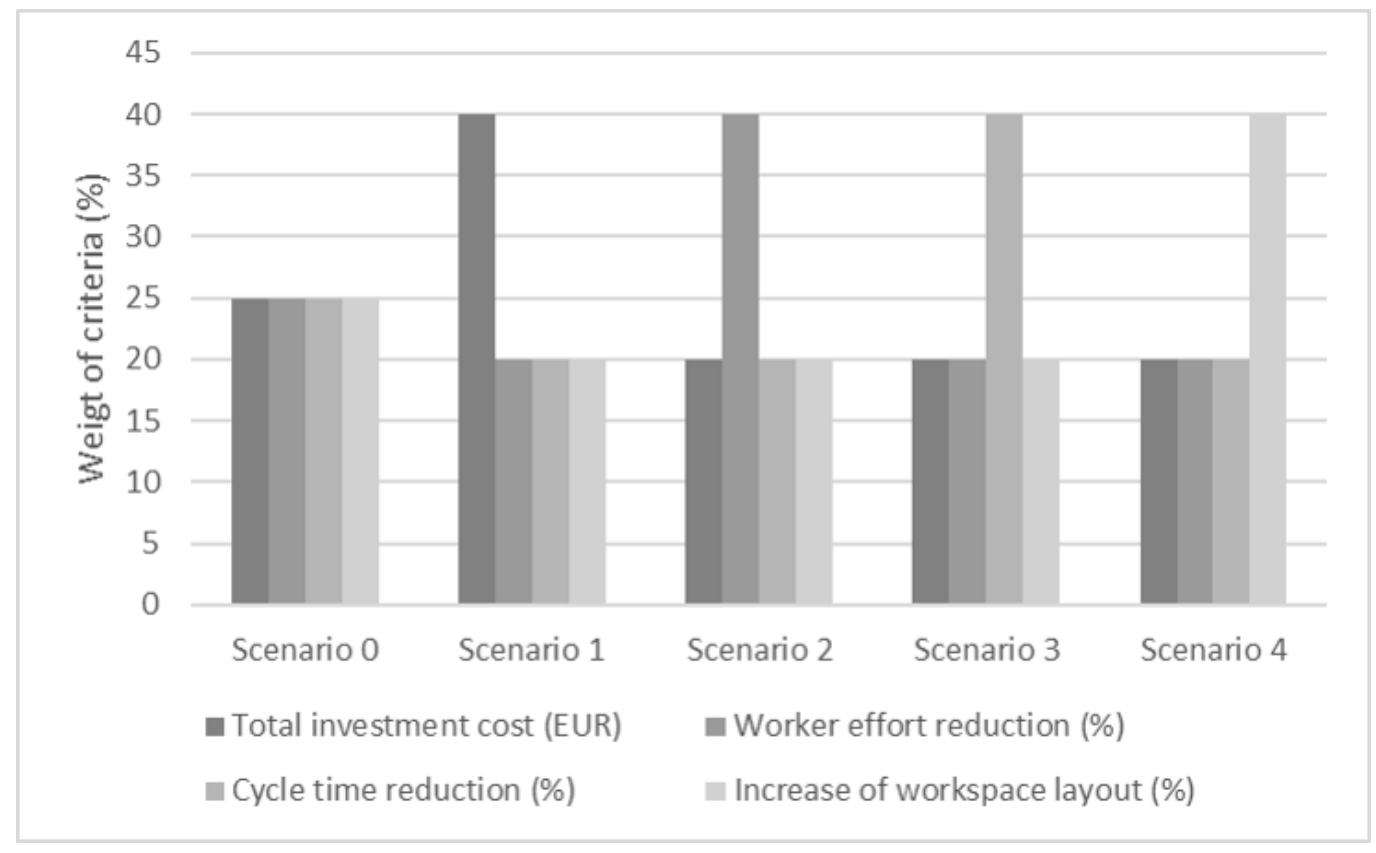

Figure 6. Different criteria weight for each scenario.

The preference function that is used for the PROMETHEE method is the linear preference function with defined indifference and preference thresholds for all criteria. Linear preference function was chosen since it is recommended for the quantitative criteria when an indifference threshold is wished to be defined, which is the situation in this study. Guidelines on how to select the appropriate preference function are given in the literature [54]. The meaning of the indifference and preference thresholds are as follows. Indifference threshold is the largest deviation that the decision-maker consider negligible, while the preference threshold is defined as the smallest deviation sufficient to generate a full preference of one alternative (option) among the other ones [54]. For example, for the presented study for the criterion "Total cost investment" the indifference threshold and preference threshold are set to 135 and 667 EUR, respectively. It means that if the difference in prices between the two observed alternatives is below EUR 135, both alternatives are equally preferred and preference of one alternative over another alternative is 0 . However, if the price of alternative 1 is cheaper than alternative 2 by EUR 667 or more, alternative 1 is absolutely preferred over alternative 2 . All other differences among alternatives that are between 135 and 667 EUR will result with preference between 0 and 1 of one alternative over another, according to defined linear function. Threshold values are defined as absolute number values because of simplicity and ease of understanding. The indifference and preference threshold for the remaining three criteria are given in Table 1.

Table 1. Threshold values for observed criteria.

\begin{tabular}{ccc}
\hline Criterion & Indifference $^{\text {Threshold }} \mathbf{~}^{\mathbf{1}}$ & Preference $^{\text {Threshold }} \mathbf{~}^{\mathbf{1}}$ \\
\hline Worker effort reduction & 10 & 20 \\
Cycle time reduction & 5 & 10 \\
Workspace layout increase & 5 & 10 \\
\hline
\end{tabular}

${ }^{1}$ Values are given in absolute amounts.

Figures 5 and 6, and Table 1 are input data for the PROMETHEE method, which is run for each scenario separately, i.e., five times. The best alternative, i.e., technologies ranking for each different scenario are compared in Figure 7 and Table 2. 


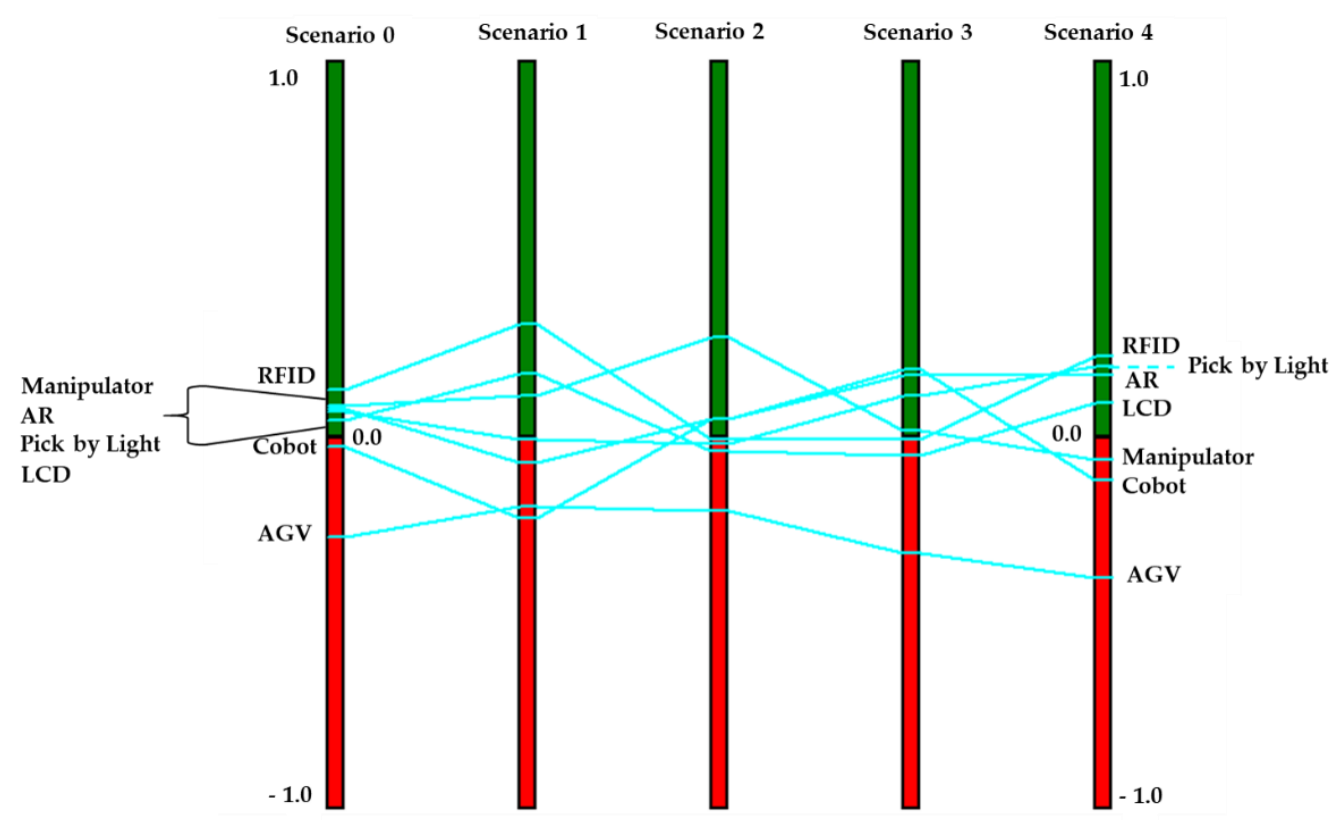

Figure 7. The rank of alternatives for each observed scenario.

Table 2. The rank of alternatives for each observed scenario.

\begin{tabular}{cccccc}
\hline & \multicolumn{4}{c}{ Scenarios (Different Weights) } \\
\cline { 2 - 6 } Rank of Alternatives & Scenario 0 & Scenario 1 & Scenario 2 & Scenario 3 & Scenario 4 \\
\hline 1. & RFID & RFID & Manipulator & Cobot & RFID \\
2. & Manipulator & LCD & AR & AR & Pick by Light \\
3. & AR & Manipulator & Cobot & Pick by Light & AR \\
4. & Pick by Light & Pick by Light & RFID & Manipulator & LCD \\
5. & LCD & AR & Pick by Light & RFID & Manipulator \\
6. & Cobot & AGV & LCD & LCD & Cobot \\
7. & AGV & Cobot & AGV & AGV & AGV \\
\hline
\end{tabular}

From the alternative rank, it is clear that the RFID presents the best compromise in scenario 0 that relates to equal criterion weight because it is the cheapest option that does not increase the layout significantly. Furthermore, RFID is the best compromise solution in scenario 1 which emphasizes cost reduction. This is expected since this option is the cheapest one of all observed technology alternatives. RFID is also the best compromise solution in scenario 4 where the criterion layout increase is minimized because this technology is among the technologies that contribute the least to increasing the workspace. On the other hand, reduction of cycle time and worker effort was important in Scenario 2 and Scenario 3, respectively. Therefore, the alternative cobot resulted as the best one in Scenario 2 since this technology significantly reduces the cycle time. Because of the enormous reduction of worker effort, the manipulator option resulted as the best one for Scenario 3. It is surprising that the AGV technology in most of the scenarios come last. It can be a little bit confusing given that these types of technologies are highly used in practice due to their numerous advantages such as faster fulfillment of customer requirements and orders, reduction of production costs. One possible reason may be that these technologies could not be effectively presented through the given criteria.

The presented analysis emphasizes the importance of decision-makers preferences, i.e., user preferences, expressed through the weights (priorities) of the selected criteria for solution evaluation. Also, this analysis emphasizes the need for individual definitions of criteria depending on the needs of the enterprise. Therefore, in the process of determining the weight of the criteria, as well as during the definition and selection of important criteria that must be taken into account in the decision process, each enterprise needs to approach 
with great caution. It is suggested that values of weights, as well as criteria, are determined in groups when they represent the conclusion of mutual work and agreement.

\section{Discussion and Conclusions}

Every modern production enterprise seeks to secure its long-term survival in relentless market competition. To achieve this, keeping up with the new trends and demands set by the market, as well as keeping up with the continuous development of technology, must be the main goals of every company. Today's rapid development of technology brings the introduction of new technologies and organizational structures defined by I4.0. Therefore, constant education of workers is required in order to help enterprises quickly adapt to newly created circumstances, i.e., to help the workers to acquire knowledge and practice for further progress of their processes and organizations. The proven concept of an efficient way for worker education is the LF concept.

Since, principal features of I4.0 is the influence of technology as an accelerant that enables individualized solution, flexibility, and cost-saving in manufacturing processes [80], the proper selection of technology that brings the most benefit to the individual production system (e.g., progress within the AL of the company) is imposed for further development of enterprises. Technology should be selected having in mind the alignment of individual criteria constraints and criteria interdependence with the expected outcomes of KPIs. Therefore, in order to better adjust the selection process to individual needs of the assembly line, the proposed framework for technology selection must include an analysis of the current state of the assembly line, its limitations and possibilities as well as future strategic goals. Considering all these parameters, the selection technology procedure will guide the decision-maker to the best compromise solution. The procedure for the selection of the most appropriate technology for the development of ALs from the perspective of I4.0 is proposed in the current study. This approach takes into account the diversity of each individual enterprise production, i.e., AL, in terms of their configuration, resources, limitations, possibilities, as well as strategic aims and business policy. It means that the proposed decision support system, besides spatial and economic assets, takes into account cost-efficiency as well as alignment of expected gains to the enterprises' strategic aims. To express the real needs of the companies, the dose of subjectivity is involved in the decisionmaking process through the definition of criterion weight through which user preferences are expressed. This subjectivism is important, because if for example, we observe the criterion "cost" (with minimization aim) and the enterprise that has a limited budget for improvements and wants a low-cost solution, then this criterion will get a high weight value. Opposite, if the enterprise is willing to invest a lot of finance into the improvement of the production process, the criterion "cost" will have a low value. As an open approach, this procedure easily adjusts to the individual possibilities and limitations of the end-user, since it is not bound to certain methods and tools. The proposed procedure could be used to gain benefits from the I4.0 by the production managers or the CEO who is well acquainted with the assembly process.

For the purposes of this paper, a gearbox AL situated in the LF characterized by a highvariety/low-volume production type is selected to describe the proposed decision support system. Multi-criteria decision support system is based on PROMETHEE which is a proven method for ranking defined alternatives in order to select the most appropriate according to the user preferences. The highest-ranked alternative presents the best compromise from the pool of possible alternatives, considering user preferences determined $a$ priori. The weights of criteria are varied in five scenarios in the gearbox AL study. For each scenario, the best option was found. Conducted validation study emphasized the impact and the importance of user preferences, as well as the need to carefully define the criteria for the evaluation of observed alternatives in the decision-making process. The selected alternative can be used immediately, but every improvement could bring certain changes. Therefore, before continuing with the following procedure iteration, assembly line balancing and 
a new spatial arrangement of the workstations are required to take into account. These changes could result in different values of criteria for the next iteration.

The current work contributes to the existing literature by expanding the research related to the implementation of I4.0 technology. The proposed procedure presents a good guideline for the end-user with little experience and limited resources during the technology selection process that is adjusted according to its need. It provides the rank of observed technology solutions with respect to the current state of the assembly line, its limitations, its possibilities as well as alignment of expected gains to enterprise strategic goals. The presented analysis in Section 4 emphasizes the importance of decision-makers' preferences, expressed through the criterion weights, as well as the need for criteria definition depending on the enterprise's possibilities and expected goals. Therefore, prior enterprise embarks on the implementation of this procedure, it is suggested that the values of weights, as well as the criteria definitions, are estimated in the groups. In that way, they represent the conclusion of mutual work and agreement. The proposed approach is iterative. It implies that when one selected solution is implemented on the assembly line, the whole selection procedure must be repeated in order to find the next most appropriate solution for the altered state since the values of the criteria for the next iteration could be changed. Accordingly, future research will be directed in the development of a broader decision support system. This support system will integrate the adaptive simulation models and propose the algorithm to select the roadmap of developed alternatives to avoid the iterative application of the procedure. The base of the future algorithm will be discrete event simulation coupled with the complexity I4.0 indicators that describe the changes of selected important parameters and according to them analyze the possible future alternatives. The proposed algorithm will take into account balancing of the assembly line, as well as other information related to the operational level (such as sequencing, scheduling, etc.).

Author Contributions: Conceptualization, N.G. and A.A.; methodology, B.B. and N.G.; validation, N.G., M.M. and A.A.; investigation, A.A. and N.G.; writing—original draft preparation, A.A.; writing-review and editing, N.G.; visualization, A.A.; supervision, M.M. and B.B.; funding acquisition, B.B. All authors have read and agreed to the published version of the manuscript.

Funding: Publishing of this research was funded by MZO-VIF INTEMON project.

Institutional Review Board Statement: Not applicable.

Informed Consent Statement: Not applicable.

Conflicts of Interest: The authors declare no conflict of interest.

\section{References}

1. Koren, Y. The Global Manufacturing Revolution: Product-Process-Business Integration and Reconfigurable Systems; John Wiley \& Sons: New York, NY, USA, 2010.

2. Pasek, Z.J.; Koren, Y.; Segall, S. Manufacturing in a global context: A graduate course on agile, reconfigurable manufacturing. Int. J. Eng. Educ. 2004, 20, 742-753.

3. Hozdić, E. Smart factory for industry 4.0: A review. Int. J. Mod. Manuf. Technol. 2015, VII, 28-35.

4. Koren, Y.; Shpitalni, M. Design of reconfigurable manufacturing systems. J. Manuf. Syst. 2010, 29, 130-141. [CrossRef]

5. Kagermann, H.; Wahlster, W.; Helbig, J. Recommendations for Implementing the Strategic Initiative INDUSTRIE 4.0; Heilmeyer und Sernau: Berlin, Germany, 2013.

6. Saniuk, S.; Grabowska, S. The concept of cyber-physical networks of small and medium enterprises under personalized manufacturing. Energies 2021, 14, 5273. [CrossRef]

7. Uhlemann, T.H.J.; Schock, C.; Lehmann, C.; Freiberger, S.; Steinhilper, R. The Digital Twin: Demonstrating the Potential of Real Time Data Acquisition in Production Systems. Procedia Manuf. 2017, 9, 113-120. [CrossRef]

8. Saniuk, S.; Grabowska, S.; Gajdzik, B.Z. Personalization of products in the industry 4.0 concept and its impact on achieving a higher level of sustainable consumption. Energies 2020, 13, 5895. [CrossRef]

9. Thoben, K.D.; Wiesner, S.A.; Wuest, T. "Industrie 4.0" and smart manufacturing-a review of research issues and application examples. Int. J. Autom. Technol. 2017, 11, 4-16. [CrossRef]

10. Andulkar, M.; Le, D.T.; Berger, U. A multi-case study on Industry 4.0 for SME's in Brandenburg, Germany. In Proceedings of the Annual Hawaii International Conference on System Sciences, Hilton Waikoloa Village, HI, USA, 3-6 January 2018; pp. 4544-4553. 
11. Weyer, S.; Schmitt, M.; Ohmer, M.; Gorecky, D. Towards industry 4.0-Standardization as the crucial challenge for highly modular, multi-vendor production systems. In IFAC-PapersOnLine; Elsevier Ltd.: Amsterdam, The Netherlands, 2015; Volume 28, pp. 579-584.

12. Welbourne, E.; Battle, L.; Cole, G.; Gould, K.; Rector, K.; Raymer, S.; Balazinska, M.; Borriello, G. Building the internet of things using RFID: The RFID ecosystem experience. IEEE Internet Comput. 2009, 13, 48-55. [CrossRef]

13. Gajdzik, B.; Grabowska, S.; Saniuk, S.; Wieczorek, T. Sustainable Development and Industry 4.0: A Bibliometric Analysis Identifying Key Scientific Problems of the Sustainable Industry 4.0. Energies 2020, 13, 4254. [CrossRef]

14. Borowski, P.F. Digitization, Digital Twins, Blockchain, and Industry 4.0 as Elements of Management Process in Enterprises in the Energy Sector. Energies 2021, 14, 1885. [CrossRef]

15. Rüßmann, M.; Lorenz, M.; Gerbert, P.; Waldner, M.; Engel, P.; Harnisch, M.; Justus, J. Future of Productivity and Growth in Manufacturing Industries; Boston Consulting Group (BCG): Boston, MA, USA, 2015.

16. Abele, E.; Metternich, J.; Tisch, M.; Chryssolouris, G.; Sihn, W.; ElMaraghy, H.; Hummel, V.; Ranz, F. Learning factories for research, education, and training. Procedia CIRP 2015, 32, 1-6. [CrossRef]

17. Krückhans, B.; Morlock, F.; Prinz, C.; Freith, S.; Kreimeier, D.; Kuhlenkötter, B. Learning Factories qualify SMEs to operate a smart factory. In Proceedings of the COMA'16 Proceedings: International Conference on Competetive Manufacturing, Stellenbosch, South Africa, 27-29 January 2016; pp. 457-460.

18. Kreimeier, D.; Morlock, F.; Prinz, C.; Krückhans, B.; Bakir, D.C. Holistic learning factories-A concept to train lean management, resource efficiency as well as management and organization improvement skills. Procedia CIRP 2014, 17, 184-188. [CrossRef]

19. Prinz, C.; Morlock, F.; Freith, S.; Kreggenfeld, N.; Kreimeier, D.; Kuhlenkötter, B. Learning Factory Modules for Smart Factories in Industrie 4.0. Procedia CIRP 2016, 54, 113-118. [CrossRef]

20. Li, F.; Yang, J.; Wang, J.; Li, S.; Zheng, L. Integration of digitization trends in learning factories. Procedia Manuf. 2019, 31, 343-348. [CrossRef]

21. Abele, E.; Chryssolouris, G.; Sihn, W.; Metternich, J.; ElMaraghy, H.; Seliger, G.; Sivard, G.; ElMaraghy, W.; Hummel, V.; Tisch, M.; et al. Learning factories for future oriented research and education in manufacturing. CIRP Ann.-Manuf. Technol. 2017, 66, 803-826. [CrossRef]

22. Lamancusa, J.S.; Jorgensen, J.E.; Zayas-Castro, J.L. Learning Factory-A new approach to integrating design and manufacturing into the engineering curriculum. J. Eng. Educ. 1997, 86, 103-112. [CrossRef]

23. Rentzos, L.; Doukas, M.; Mavrikios, D.; Mourtzis, D.; Chryssolouris, G. Integrating manufacturing education with industrial practice using teaching factory paradigm: A construction equipment application. Procedia CIRP 2014, 17, 189-194. [CrossRef]

24. Wagner, U.; AlGeddawy, T.; ElMaraghy, H.; Müller, E. Product family design for changeable learning factories. Procedia CIRP 2014, 17, 195-200. [CrossRef]

25. Veza, I.; Gjeldum, N.; Mladineo, M. Lean learning factory at FESB_University of Split. Procedia CIRP 2015, 32, 132-137. [CrossRef]

26. Womack, J.P.; Jones, D.T.; Roos, D. The Machine that Changed the World: The Story of Lean Production-Toyota's Secret Weapon in the Global Car Wars that is Now Revolutionizing World Industry; Simon and Schuster: New York, NY, USA, 2007.

27. Dombrowski, U.; Richter, T.; Krenkel, P. Interdependencies of Industrie 4.0 \& Lean Production Systems: A Use Cases Analysis. Procedia Manuf. 2017, 11, 1061-1068. [CrossRef]

28. Rossini, M.; Costa, F.; Tortorella, G.L.; Portioli-Staudacher, A. The interrelation between Industry 4.0 and lean production: An empirical study on European manufacturers. Int. J. Adv. Manuf. Technol. 2019, 102, 3963-3976. [CrossRef]

29. Salah, B.; Khan, S.; Ramadan, M.; Gjeldum, N. Integrating the concept of industry 4.0 by teaching methodology in industrial engineering curriculum. Processes 2020, 8, 1007. [CrossRef]

30. Wilson, J.M. Henry Ford vs. assembly line balancing. Int. J. Prod. Res. 2014, 52, 757-765. [CrossRef]

31. Bortolini, M.; Ferrari, E.; Gamberi, M.; Pilati, F.; Faccio, M. Assembly system design in the Industry 4.0 era: A general framework. In IFAC-PapersOnLine; Elsevier B.V.: Amsterdam, The Netherlands, 2017; Volume 50, pp. 5700-5705.

32. Miqueo, A.; Torralba, M.; Yagüe-Fabra, J.A. Lean manual assembly 4.0: A systematic review. Appl. Sci. 2020, 10, 8555. [CrossRef]

33. Gregor, M.; Medvecky, S. Digital Factory-Theory and Practice. In Engineering the Future; Dudas, L., Ed.; IntechOpen: London, UK, 2010; pp. 355-376.

34. Hou, L.; Wang, X.; Bernold, L.; Love, P.E.D. Using Animated Augmented Reality to Cognitively Guide Assembly. J. Comput. Civ. Eng. 2013, 27, 439-451. [CrossRef]

35. Cohen, Y.; Faccio, M.; Galizia, F.G.; Mora, C.; Pilati, F. Assembly system configuration through Industry 4.0 principles: The expected change in the actual paradigms. In IFAC Paper Online; Elsevier B.V.: Amsterdam, The Netherlands, 2017; Volume 50, pp. 14958-14963.

36. Peron, M.; Sgarbossa, F.; Strandhagen, J.O. Decision support model for implementing assistive technologies in assembly activities: A case study. Int. J. Prod. Res. 2020, 1-27. [CrossRef]

37. Ranz, F.; Hummel, V.; Sihn, W. Capability-based Task Allocation in Human-robot Collaboration. Procedia Manuf. 2017, 9, 182-189. [CrossRef]

38. Mourtzis, D.; Zogopoulos, V.; Xanthi, F. Augmented reality application to support the assembly of highly customized products and to adapt to production re-scheduling. Int. J. Adv. Manuf. Technol. 2019, 105, 3899-3910. [CrossRef]

39. Battini, D.; Faccio, M.; Persona, A.; Sgarbossa, F. New methodological framework to improve productivity and ergonomics in assembly system design. Int. J. Ind. Ergon. 2011, 41, 30-42. [CrossRef] 
40. Antonelli, D.; Astanin, S.; Bruno, G. Applicability of Human-Robot Collaboration to Small Batch Production. In Proceedings of the Collaboration in a Hyperconnected World. PRO-VE 2016, Porto, Portugal, 3-5 October 2016; Hamideh, A., Luis, C.-M., António, L.S., Eds.; Springer: Cham, Switzerland, 2016; Volume 1, pp. $24-32$.

41. Faccio, M.; Bottin, M.; Rosati, G. Collaborative and traditional robotic assembly: A comparison model. Int. J. Adv. Manuf. Technol. 2019, 102, 1355-1372. [CrossRef]

42. Weckenborg, C.; Kieckhäfer, K.; Müller, C.; Grunewald, M.; Spengler, T.S. Balancing of assembly lines with collaborative robots. Bus. Res. 2020, 13, 93-132. [CrossRef]

43. Fowler, D.; Gurau, V.; Cox, D. Bridging the gap between automated manufacturing of fuel cell components and robotic assembly of fuel cell stacks. Energies 2019, 12, 3604. [CrossRef]

44. Uva, A.E.; Gattullo, M.; Manghisi, V.M.; Spagnulo, D.; Cascella, G.L.; Fiorentino, M. Evaluating the effectiveness of spatial augmented reality in smart manufacturing: A solution for manual working stations. Int. J. Adv. Manuf. Technol. 2018, 94, 509-521. [CrossRef]

45. Horejsi, P.; Novikov, K.; Simon, M. A smart factory in a smart city: Virtual and augmented reality in a smart assembly line. IEEE Access 2020, 8, 94330-94340. [CrossRef]

46. Wolfartsberger, J.; Haslwanter, J.; Lindorfer, R. Perspectives on Assistive Systems for Manual Assembly Tasks in Industry. Technologies 2019, 7, 12. [CrossRef]

47. Hou, L.; Wang, X.; Truijens, M. Using Augmented Reality to Facilitate Piping Assembly: An Experiment-Based Evaluation. J. Comput. Civ. Eng. 2015, 29, 05014007. [CrossRef]

48. Yoo, S.K.; Kim, B.Y. A decision-making model for adopting a cloud computing system. Sustainability 2018, 10, 2952. [CrossRef]

49. Marinho, M.; Prakash, V.; Garg, L.; Savaglio, C.; Bawa, S. Effective cloud resource utilisation in cloud erp decision-making process for industry 4.0 in the united states. Electronics 2021, 10, 959. [CrossRef]

50. Majdzik, P.; Witczak, M.; Lipiec, B.; Banaszak, Z. (IMS2019)Integrated fault-tolerant control of assembly and automated guided vehicle-based transportation layers. Int. J. Comput. Integr. Manuf. 2021, 1-18. [CrossRef]

51. Erdogan, M.; Ozkan, B.; Karasan, A.; Kaya, I. Selecting the Best Strategy for Industry 4.0 Applications with a Case Study. In Industrial Engineering in the Industry 4.0 Era; Springer: Cham, Switzerland, 2018; pp. 109-119.

52. Rabbani, M.; Heidari, R.; Farrokhi-Asl, H. A bi-objective mixed-model assembly line sequencing problem considering customer satisfaction and customer buying behaviour. Eng. Optim. 2018, 50, 2123-2142. [CrossRef]

53. Abdullah, L.; Chan, W.; Afshari, A. Application of PROMETHEE method for green supplier selection: A comparative result based on preference functions. J. Ind. Eng. Int. 2019, 15, 271-285. [CrossRef]

54. Brans, J.-P.; Smet, Y. De PROMETHEE METHODS. In Multiple Criteria Decision Analysis; Springer: New York, NY, USA, 2016; pp. 187-219.

55. Hu, S.J.; Ko, J.; Weyand, L.; Elmaraghy, H.A.; Lien, T.K.; Koren, Y.; Bley, H.; Chryssolouris, G.; Nasr, N.; Shpitalni, M. Assembly system design and operations for product variety. CIRP Ann.-Manuf. Technol. 2011, 60, 715-733. [CrossRef]

56. Roof, K.T. Elon Musk Says 'Humans are Underrated', Calls Tesla's ‘Excessive Automation' a 'Mistake'. Available online: https:// techcrunch.com/2018/04/13/elon-musk-says-humans-are-underrated-calls-teslas-excessive-automation-a-mistake/ (accessed on 14 April 2021).

57. Gjeldum, N.; Salah, B.; Aljinovic, A.; Khan, S. Utilization of Industry 4.0 Related Equipment in Assembly Line Balancing Procedure. Processes 2020, 8, 864. [CrossRef]

58. Oztemel, E.; Gursev, S. Literature review of Industry 4.0 and related technologies. J. Intell. Manuf. 2020, 31, 127-182. [CrossRef]

59. Ma, H.; Wang, Y.; Wang, K. Automatic detection of false positive RFID readings using machine learning algorithms. Expert Syst. Appl. 2018, 91, 442-451. [CrossRef]

60. Syberfeldt, A.; Danielsson, O.; Holm, M.; Wang, L. Visual Assembling Guidance Using Augmented Reality. Procedia Manuf. 2015, 1, 98-109. [CrossRef]

61. Stockinger, C.; Steinebach, T.; Petrat, D.; Bruns, R.; Zöller, I. The effect of pick-by-light-systems on situation awareness in order picking activities. Procedia Manuf. 2020, 45, 96-101. [CrossRef]

62. De Vries, J.; De Koster, R.; Stam, D. Exploring the role of picker personality in predicting picking performance with pick by voice, pick to light and RF-terminal picking. Int. J. Prod. Res. 2016, 54, 2260-2274. [CrossRef]

63. Fiorentino, M.; Uva, A.E.; Gattullo, M.; Debernardis, S.; Monno, G. Augmented reality on large screen for interactive maintenance instructions. Comput. Ind. 2014, 65, 270-278. [CrossRef]

64. Zhu, Z.; Liu, C.; Xu, X. Visualisation of the digital twin data in manufacturing by using augmented reality. Procedia CIRP 2019, 81, 898-903. [CrossRef]

65. Schroeder, G.; Steinmetz, C.; Pereira, C.E.; Muller, I.; Garcia, N.; Espindola, D.; Rodrigues, R. Visualising the digital twin using web services and augmented reality. In Proceedings of the IEEE International Conference on Industrial Informatics (INDIN), Poitiers, France, 19-21 July 2016; IEEE: Piscataway, NJ, USA, 2016; pp. 522-527.

66. Sepasgozar, S.M.E. Digital twin and web-based virtual gaming technologies for online education: A case of construction management and engineering. Appl. Sci. 2020, 10, 4678. [CrossRef]

67. Lalik, K.; Flaga, S. A real-time distance measurement system for a digital twin using mixed reality goggles. Sensors 2021, 21, 7870. [CrossRef] [PubMed] 
68. Gwon, S.H.; Oh, S.C.; Huang, N.; Hong, S.K. Advanced RFID application for a mixed-product assembly line. Int. J. Adv. Manuf. Technol. 2011, 56, 377-386. [CrossRef]

69. Djuric, A.M.; Rickli, J.L.; Urbanic, R.J. A Framework for Collaborative Robot (CoBot) Integration in Advanced Manufacturing Systems. SAE Int. J. Mater. Manuf. 2016, 9, 457-464. [CrossRef]

70. Villani, V.; Pini, F.; Leali, F.; Secchi, C. Survey on human-robot collaboration in industrial settings: Safety, intuitive interfaces and applications. Mechatronics 2018, 55, 248-266. [CrossRef]

71. ElMaraghy, H.; ElMaraghy, W. Smart Adaptable Assembly Systems. Procedia CIRP 2016, 44, 4-13. [CrossRef]

72. Tsarouchi, P.; Matthaiakis, A.S.; Makris, S.; Chryssolouris, G. On a human-robot collaboration in an assembly cell. Int. J. Comput. Integr. Manuf. 2017, 30, 580-589. [CrossRef]

73. Krüger, J.; Lien, T.K.; Verl, A. Cooperation of human and machines in assembly lines. CIRP Ann.-Manuf. Technol. 2009, 58, 628-646. [CrossRef]

74. Cherubini, A.; Passama, R.; Crosnier, A.; Lasnier, A.; Fraisse, P. Collaborative manufacturing with physical human-robot interaction. Robot. Comput. Integr. Manuf. 2016, 40,1-13. [CrossRef]

75. Gjeldum, N.; Aljinovic, A.; Crnjac Zizic, M.; Mladineo, M. Collaborative robot task allocation on an assembly line using the decision support system. Int. J. Comput. Integr. Manuf. 2021, 1-17. [CrossRef]

76. Wang, Z.; Lou, X.; Yu, Z.; Guo, B.; Zhou, X. Enabling non-invasive and real-time human-machine interactions based on wireless sensing and fog computing. Pers. Ubiquitous Comput. 2019, 23, 29-41. [CrossRef]

77. Murukesan, L.; Murugappan, M.; Iqbal, M.; Saravanan, K. Machine learning approach for sudden cardiac arrest prediction based on optimal heart rate variability features. J. Med. Imaging Health Inform. 2014, 4, 521-532. [CrossRef]

78. Clark, C.C.T.; Barnes, C.M.; Stratton, G.; McNarry, M.A.; Mackintosh, K.A.; Summers, H.D. A Review of Emerging Analytical Techniques for Objective Physical Activity Measurement in Humans. Sport. Med. 2017, 47, 439-447. [CrossRef]

79. Bláfoss, R.; Sundstrup, E.; Jakobsen, M.D.; Brandt, M.; Bay, H.; Andersen, L.L. Physical workload and bodily fatigue after work: Cross-sectional study among 5000 workers. Eur. J. Public Health 2019, 29, 837-842. [CrossRef] [PubMed]

80. Wang, R. Deloitte's Study on Industry 4.0: Industry 4.0 Challenges and Solutions for the Digital Transformation and Use of Exponential Technologies; Zurich Deloitte AG: Zurich, Switzerland, 2015. 